\title{
Comparative Effectiveness of Cognitive-Behavioral Therapy and Dialectical Behavior Therapy on Emotion Regulation, Positive and Negative Affection, Aggressive and Self-Harm Behaviors of 13-16-Year-Old Female Students
}

\author{
Sara Ghorbani*1; Alireza Salemi Khameneh ${ }^{2}$; Alireza Motahedi ${ }^{3}$; Zahra Alipour ${ }^{4}$ \\ ${ }^{1}$ Department of Psychology, Faculty of Humanities, Islamic Azad University of Varamin, Tehran, Iran \\ ${ }^{2}$ Department of Psychology, Faculty of Humanities, Islamic Azad University of Varamin, Tehran, Iran \\ ${ }^{3}$ Department of Psychology, Faculty of Humanities, Islamic Azad University of Varamin, Tehran, Iran \\ ${ }^{4}$ Department of Psychology, Faculty of Humanities, Payam noor University of Nazar Abad, Alborz, Iran
}

Email:ghorbanisara86@gmail.com¹; dr.arsa@yahoo.com²; drmotahedy@gmail.com³; z.alipour89@gmail.com ${ }^{4}$

${ }^{*}$ Corresponding Author: Sara Ghorbani

http://dx.doi.org/10.18415/ijmmu.v7i9.1883

\begin{abstract}
This study was aimed to compare the effectiveness of cognitive-behavioral therapy with dialectical behavior therapy on emotion regulation, positive and negative affection, aggressive and selfharm behaviors of 13 to 16-year-old female students. The results showed that both CBT and DBT have a significant effect on increasing emotional regulation and positive affect, and decreasing negative affect, reducing aggressive behavior and self-harm. Also there was no significant difference between two treatments in increasing the positive affection and decreasing negative affection, but the effect of DBT on increasing emotional regulation and reducing self-harm and aggressive behaviors was significantly more than CBT.
\end{abstract}

Keywords: Cognitive-Behavioral Therapy; Dialectical Behavior Therapy; Emotion Regulation; Positive and Negative Affection; Aggressive Behavior; Self-Harm

\section{Introduction}

Childhood and adolescence are the perfect years to recognize a person's problems, timely intervention, and prevent future emotional, social, and academic problems. Timely intervention and modification of adolescent discordant behaviors in this sensitive period may enhance relationships between the individual fosters positive emotions and popularity with peers and adults and prepares the adolescent for acceptance of future responsibilities (Nasirzadeh \& Roshan, 2010), on the other hand, the period of adolescence and the conflicts that result from it may lead to a variety of traumas examples include the emergence and negative emotions, aggression and self-harm. People who have less emotion 
regulation ability are more aggressive. Various studies have shown that positive emotions have a positive and significant relationship with different aspects of mental health and play an important role in the prevention of physical and mental disorders and negative emotions have a positive relationship with mental disorders and has an impact on creating and persisting of psychological abnormalities (Yosefi, 2015). Kortte (2010), in a study, showed that negative feelings and emotions such as anger, sadness, and disgust were negative and reverse, and positive emotions such as positive and direct optimism, predict mental health. On the other hand, Sadeghi, Shahri, Khaleghi Kiadehi, Asadian, and Pirani (2015), found that negative emotions underlie risk associated with aggressive behaviors in students. Aggression-related issues such as coping behaviors, hostility, and anger are the main causes of adolescent and child referral to counseling and psychotherapy centers (Sukhodolsky, Kassinove \& Gorman, 2004). From a social psychology point of view, aggression involves behaviors that cause self-harm or physical harm to others. In other words, aggression is the deliberate infliction of some form of harm to oneself and others (Ghadiri, 2006). Aggressive students are usually incapable of controlling their behavior and have difficulty reading emotional symptoms, understanding the other's perspective, and managing anger. These people do not have the behavioral skills needed to provide adequate answers to problems and are deficient in conflict resolution skills (Ramazani, Rahmani Nia, Boroumand, 2009). Hosin (2001) says that aggression is verbal or physical behavior whose purpose is to harm another person or creature. Fekri's (2015) research has shown that there is a significant relationship between negative emotions and selfharm behaviors. Self-harm involves repeated bodily harm, such as beating, biting, scratching, or tearing the skin and swallowing harmful or dangerous substances, or in other words, deliberate danger, non-fatal, or poisoning with knowledge of its potential danger. Self-harm is a potential behavioral disorder and this is the reactionary behavior towards the stimuli and one wants to interact with others to be taken into consideration and is an aspect of self-disclosure and exposure. This behavior may occur at all ages, especially in adolescence (Gusman, 2014). Foroughi's (2017) research also represented that one of the variables related to aggressive behaviors and positive and negative affect in students is emotional regulation. Emotion regulation is defined as the process of modifying one or more aspects of emotional experiences or responses (Fosca, 2008). Emotion regulation is a pivotal process for all aspects of human functioning and plays a vital role in the ways that individuals cope with stressful experiences and experience happiness (McDermott, Tull, Gratz, Daughters \& Lejuez, 2009). Research has represented that emotion regulation strategies are associated with psychological distress. Predicts future adaptation, and focusing on emotion regulation skills can be effective in predicting and treating affective disorders related to mental health problems (Berking, Orth \& Wupperman, 2008).

Other research has shown that emotion regulation predicts positive adaptation and management of anger and aggressive behaviors. Repeat as an Emotional regulation is associated with high well-being and mental health. Providing psychological interventions to manage emotions, enhancing positive emotions, and reduce aggressive behaviors that lead to harm to oneself and others is essential. One of the effective interventions in this field is cognitive-behavioral therapy. Researchers such as Lazarous, Fox, McMalin, and MichenBam believe that learning, maintaining, and eliminating behaviors occur through systems that interact with external events and cognitive processes (Seif, 2014). Thus, cognitive-behavioral therapists, like cognitive therapists, view irrational thinking and destructive self-talk as the source of psychological problems, but unlike cognitive therapists, they use more organized behavioral techniques to change cognitive processes (Rosenhan \& Seligman, 2012). Better yet, therapists emphasize changing attitudes and self-help not only on cognitive restructurings such as changing false expectations, maladaptive schemas, automatic negative thoughts, negative self-talk, and irrational beliefs. Rather, they emphasize the teaching of social skills such as self-expression, problem-solving, muscle relaxation, interpersonal skills (Baker \& Scarth, 2012). The stages leading up to their response are mostly based on their instincts and emotions. As clients experience success in problem-solving, their self-control will increase (Khodayari, 2014). Another effective intervention in this area is dialectical behavior therapy. Dialectical behavior therapy is a cognitive-behavioral approach that was first devised to treat borderline personality disorder. This approach combines cognitive, behavioral, and supportive interventions based on the 
principle of change with the teachings and techniques of Eastern philosophy that are based on the acceptance principle, and thus incorporates four interventional components (Linehan \& Dexter-Mazze, 2012). In this treatment, fundamental alertness and tolerance of suffering and distress are the components of acceptance, emotional regulation, and interpersonal efficacy as components of change in dialectical behavior therapy (Narimani, Bagiyan-Kulemarez, Ahadi \& Abolghasemi, 2014). Therefore, this study emphasizes the importance of primary prevention in identifying traumatic factors in high-risk behaviors such as aggression and self-harm in adolescence, and on the other, recognizing the factors of positive and negative emotions in harm reduction and looking at different therapeutic approaches based on cognitive approaches, such as Cognitive-Behavioral Therapy and Dialectical Behavior Therapy in solving these problems and comparing the impact of these approaches and considering the needs of organs and organizations such as education, well-being, etc. to research results, and lack of coherent and applied research in Specifically, the researcher aims to compare the effectiveness of cognitive-behavioral therapy and dialectical behavior therapy. Focus on emotion regulation, positive and negative affect, aggressive behavior, and self-harm in female students.

\section{Method}

The research design was pre-test and post-test with a control group. The statistical population of the study included all female students of 13-16 years old high school. The sampling method was multistage random sampling. One group was randomly assigned to the experimental groups and the other to the control group. Inclusion and exclusion criteria were 13- to 16-year-old female students, aggression score, high self-esteem and negative emotion score, low emotion regulation score and low positive emotion, lack of co-participation in other treatment programs, and no individual counseling or drug therapy, desire, and satisfaction to participate in research. In both groups, positive and negative affect questionnaire, Buss and Perry aggression questionnaire, self-injury questionnaire (SHI), and emotion regulation questionnaire were conducted as the pre-test. After completing the experimental intervention in both groups the questionnaires were re-administered as post-test and finally, the data were entered into the software and summary of the content of the sessions, and the activities performed in each session are presented in Table 1.

\section{Table 1- Titles of sessions}

\section{Titles of sessions of Dialectical Behavior Therapy}

\begin{tabular}{|l|l|}
\hline Session 1 & $\begin{array}{l}\text { Introducing group members to each other and detailing how to work and plan for future } \\
\text { meetings and assignments of each group member }\end{array}$ \\
\hline Session 2 & $\begin{array}{l}\text { Mindfulness skills training and the first skill of this group to be trained is a rational } \\
\text { mind }\end{array}$ \\
\hline Session 3 & $\begin{array}{l}\text { Mindfulness skills training and the second skill of this group being trained is emotional } \\
\text { mind }\end{array}$ \\
\hline Session 4 & $\begin{array}{l}\text { Mindfulness skills training and the third skill of this group that is being trained is wise } \\
\text { mind }\end{array}$ \\
\hline Session 5 & $\begin{array}{l}\text { Teaching first-class skills of mindfulness that includes the "what" skills class that } \\
\text { involves observing, describing, and participating }\end{array}$ \\
\hline Session 6 & $\begin{array}{l}\text { Teaching Second-class skills of mindfulness , which includes the "how" skill class, } \\
\text { which includes being non-judgmental- mindfulness itself and working effectively }\end{array}$ \\
\hline Session 7 & $\begin{array}{l}\text { Effective interpersonal skills training that includes strengthening the skills of saying no } \\
\text { - the ability to maintain relationships and maintain self-respect }\end{array}$ \\
\hline Session 8 & $\begin{array}{l}\text { Training for distress tolerance skills (aggression and self-harm) that involves both } \\
\text { activity and participation skills }\end{array}$ \\
\hline
\end{tabular}




\begin{tabular}{|c|c|}
\hline Session 9 & $\begin{array}{l}\text { Training for distress tolerance skills which include two skills of comparison and } \\
\text { emotion }\end{array}$ \\
\hline Session 10 & $\begin{array}{l}\text { Training for distress tolerance skills which include three subsidence skills-thoughts- } \\
\text { senses }\end{array}$ \\
\hline Session 11 & $\begin{array}{l}\text { Training emotion regulation skills, reducing emotional distress and improving positive } \\
\text { emotions }\end{array}$ \\
\hline Session 12 & Summary of group discussions and answers to group questions \\
\hline \multicolumn{2}{|r|}{ Titles of sessions of Cognitive Behavior Therapy } \\
\hline Session 1 & $\begin{array}{l}\text { Introducing members to each other, introducing group rules, stating the goals of the } \\
\text { meetings and the overall schedule of the meetings, and explaining the tasks of the } \\
\text { participants }\end{array}$ \\
\hline Session 2 & $\begin{array}{l}\text { Introducing the group to positive and negative emotions, focusing on emotions, } \\
\text { identifying their motivating situations, and giving assignments (behavior analysis to } \\
\text { identify stimuli) }\end{array}$ \\
\hline Session 3 & $\begin{array}{l}\text { Implementation of cognitive-behavioral techniques (Socratic questioning, cognitive } \\
\text { reconstruction ,etc.), Model training in attention to thoughts and beliefs, Attention to } \\
\text { physical and emotional symptoms }\end{array}$ \\
\hline Session 4 & $\begin{array}{l}\text { Paying attention to thoughts and beliefs before emotions, paying attention to behaviors } \\
\text { after thoughts and beliefs, helping to change thinking and examining some basic beliefs }\end{array}$ \\
\hline Session 5 & $\begin{array}{l}\text { Peace learning, relaxation training (Jacobson's progressive relaxation was taught to the } \\
\text { subjects and performed in groups and the audio file was given to the subjects to practice } \\
\text { at home) }\end{array}$ \\
\hline Session 6 & $\begin{array}{l}\text { Training in logical thought analysis techniques and applying daily thought recording } \\
\text { techniques, Converting attention, Benefits and disadvantages analysis, Downward } \\
\text { arrow practice, Mental imagery, Identifying and changing destructive behaviors after } \\
\text { negative thoughts and self-talk By slowing down the process of negative thoughts and } \\
\text { replacing them with rational and efficient thoughts and positive self-talk }\end{array}$ \\
\hline Session 7 & $\begin{array}{l}\text { Continue to identify and change core beliefs, behavioral of negotiating emotions, } \\
\text { relaxation, delayed reaction, focus on breathing, problem-solving training and how to } \\
\text { respond appropriately to different situations and emotions management }\end{array}$ \\
\hline Session 8 & $\begin{array}{l}\text { Assertiveness training and muscle relaxation training, training in cognitive errors and } \\
\text { coping }\end{array}$ \\
\hline Session 9 & $\begin{array}{l}\text { Use problem-solving guides and review members' progress in achieving goals, training } \\
\text { in coping skills, and preventing them from returning to old patterns }\end{array}$ \\
\hline Session 10 & $\begin{array}{l}\text { Overview of the techniques taught and the results summarized, emphasis on interval } \\
\text { training and post-test implementation }\end{array}$ \\
\hline
\end{tabular}




\section{Measuring tools}

\section{Positive and negative affects questionnaire}

The questionnaire has 20 items and was developed by Watson et al, designed to measure both positive and negative mood dimensions (Watson, Clark \& Tellegen, 1998). The items respond on a 5degree scale. This tool completes self-assessment and by modifying its instructions one can measure the emotional state or attribute dimension. Cronbach's alpha coefficients of positive and negative affect subscales were 0.86 to 0.90 and 0.87 to 0.84 , respectively. The retest reliability coefficient for the positive and negative affect was reported 0.68 to 0.47 and 0.71 to 0.39 , respectively. The alpha coefficient of the Persian version was 0.87 (Mohammadi, Birashk \& Gharraee, 2013).

\section{Buss \& Perry aggression Questionnaire}

The Buss and Perry Aggression Questionnaire was constructed by Bass and Perry and validated by Mohammedi. This tool is a self-report tool consisting of 29 phrases and 4 subscales called physical aggression, verbal aggression, anger, and hostility and scored on a 5-point scale (strongly agree $=5$ to strongly disagree $=1$ ) (Mohammadi, 2007). This questionnaire has very good internal consistency. Buss and Perry reported 0.89 as an internal consistency coefficient and 0.80 as reliability using the test-retest method (Shakibaei, Tehrani doust, Shahrivar \& Asaari, 2004). Correlation of subscales of this questionnaire with each other and with the whole scale, ranging from 0.25 to 0.45 , indicated the appropriate validity of this instrument. Mohammedi also test-retest reliability coefficients for the whole questionnaire were 0.78 and for the subscales ranged from 0.61 to 0.74 . The concurrent validity of this questionnaire was estimated to be 0.34 using the General Psychiatric Injury Scale, which was significant $(\mathrm{P}<0.001)$.

\section{Self-Injury Questionnaire (SHI)}

The Self-Injury Questionnaire by Sansone et al is a 22-question questionnaire that is answered yes/no. The questionnaire assesses behaviors that are deliberately harmful to themselves, such as drug or alcohol abuse, self-harm, self-injury, or intentional job loss. The validity of the questionnaire in Cronbach's alpha method was estimated to be 0.83 by Sansone et al. In a study by Tahbaz Hoseinzadeh, Ghorbani \& Nabavi (2011), in which self-destructive and self-efficacy personality traits were compared in patients with Multiple Sclerosis and healthy controls, the Cronbach's alpha of 0.74 was obtained.

\section{Emotion Regulation Questionnaire}

It is provided by Gross and John (2003). The scale is composed of 10 items with two subscales of reassessment (6 items) and subscale (4 items). Responses are based on a Likert scale (seven points), from strongly disagree (1) to strongly agree (7). Cronbach's alpha coefficient of 0.79 for reassessment and 0.73 for suppression and retest validity after 3 months for a total scale of 0.69 have been reported (Gross, 2001). Internal consistency coefficient of this scale in Milan State University staff and Catholic staff for reassessment on a scale from 0.48 to 0.68 and for suppression (0.24) and negative affect (-0.14) and suppression with positive affect scale (-0.15) and negative emotions (0.04) have been reported (Balzarotti, John \& Gross, 2010). The Persian version of the Gross and John Emotional Adjustment Questionnaire has been standardized in Iranian culture by Ghasempour, Ilbeigi, and Hassanzadeh (2012). In this study, the validity of the scale based on the internal consistency method (with Cronbach's alpha range of 0.06 to 0.81 ) and validity of the questionnaire through principal component analysis or using Varimax rotation, a correlation between the two subscales $(r=0.13)$ and optimal criterion validity have been reported. 


\section{Findings}

One of the assumptions to be considered in the multivariate analysis of covariance analysis is the homogeneity of the variance of dependent variables at independent variable levels. Box test was used to measure the equality of covariance matrices in the dependent variables. The information on this test can be found in Table 2 .

Table 2- Box test

\begin{tabular}{|c|c|}
\hline Statistic & 71.375 \\
\hline F & 1.952 \\
\hline DF 1 & 30 \\
\hline DF 2 & 5.278 \\
\hline P & 0.001 \\
\hline
\end{tabular}

As can be seen, the box test is significant, indicating that the assumption of the equality of variances is not observed at the variable level of the criterion. It should be noted, however, that the box test, like all statistical tests, is very sensitive to sample size and shows significant differences (SPSS Guide). To further investigate which of the variance exactly corresponds to one of the predictor variables, the Levene's test was used to test the variance equality for each variable separately, the results of which are shown in Table 3.

Table 3- Levene's test

\begin{tabular}{|c|c|c|c|c|}
\hline Scale & Statistic & DF 1 & DF 2 & P \\
\hline Emotion Regulation & 1.449 & 2 & 41 & 0.247 \\
\hline Aggression & 2.427 & 2 & 41 & 0.052 \\
\hline Negative Affect & 0.519 & 2 & 41 & 0.599 \\
\hline Positive Affect & 2.915 & 2 & 41 & 0.056 \\
\hline Self-Harm & 1.804 & 2 & 41 & 0.051 \\
\hline
\end{tabular}

Levene's test did not show significant differences between the variables. Therefore, based on the non-significance of the Levene's test, the hypothesis of normality of data and the equality of variances can be considered and the covariance analysis test can be used. Table 4 presents the mean and standard deviation of the dependent variables for all subjects, as well as the experimental and control groups separately. If the illative tests for the differences between groups are significant, the data in this table will be used to interpret the test significantly and identify the superiority of the groups to each other.

Table 4- The mean and standard deviation of control and experimental groups

\begin{tabular}{|c|c|c|c|c|c|c|c|c|}
\hline \multirow{2}{*}{ Scale } & \multicolumn{2}{|c|}{ Control Group } & \multicolumn{2}{c|}{ DBT Group } & \multicolumn{2}{c|}{ CBT Group } & \multicolumn{2}{c|}{ Total } \\
\cline { 2 - 9 } & Mean & SD & Mean & SD & Mean & SD & Mean & SD \\
\hline Emotion Regulation & 30.43 & 6.009 & 46.27 & 3.731 & 42.93 & 3.240 & 39.41 & 7.595 \\
\hline Aggression & 74.43 & 18.806 & 100.67 & 12.579 & 108.27 & 9.903 & 94.91 & 20.018 \\
\hline Negative Affect & 32.29 & 6.031 & 19.13 & 2.722 & 19.47 & 3.270 & 23.43 & 7372 \\
\hline Positive Affect & 30.93 & 8.194 & 32.80 & 3.342 & 35.33 & 3.658 & 33.07 & 5.621 \\
\hline Self-Harm & 29.14 & 3.085 & 21.33 & 1.047 & 24.87 & 1.125 & 25.02 & 3.434 \\
\hline
\end{tabular}


Multivariate analysis of covariance (MANCOVA) was used to investigate the effect of experimental interventions. The test was performed on the collected data and the results are presented in Table 5:

Table 5-The result of (MANCOVA)

\begin{tabular}{|c|c|c|c|c|c|c|}
\hline Squared Eta & P & DF Error & DF & F & Amount & Statistic \\
\hline 0.627 & 0.0001 & 66 & 10 & 11.095 & 1.254 & Pillai's trace \\
\hline 0.724 & 0.0001 & 64 & 10 & 16.783 & 0.076 & Wilks' Lambda \\
\hline 0.796 & 0.0001 & 62 & 10 & 24.144 & 7.788 & Hotelling's trace \\
\hline 0.878 & 0.0001 & 33 & 5 & 47.424 & 7.185 & $\begin{array}{c}\text { Roy's largest } \\
\text { root }\end{array}$ \\
\hline
\end{tabular}

As can be seen in the significant levels column of the output analysis of covariance analysis output table, all four statistics are significant $(\mathrm{P}<0.0001)$. This means that there is a real statistical difference between the three groups. Following the multivariate test for further elucidation and more detailed findings, use of the univariate test for individual analysis of each dependent variable and comparison of three groups (two experimental and one control group) for each dependent variable (emotion regulation, Positive Affect, Negative Affect, Aggression, Self-Injury) univariate covariance test was used.

Table 6- The result of univariate analysis of covariance

\begin{tabular}{|c|c|c|c|c|c|c|}
\hline Squared Eta & $\mathrm{P}$ & $\mathrm{F}$ & $\begin{array}{c}\text { Mean } \\
\text { squares }\end{array}$ & DF & $\begin{array}{c}\text { The sum of } \\
\text { the squares }\end{array}$ & $\begin{array}{c}\text { The } \\
\text { dependent } \\
\text { variable }\end{array}$ \\
\hline 0.779 & 0.0001 & 63.335 & 127.035 & 2 & 254.071 & Self_Harm \\
\hline 0.446 & 0.0001 & 14.480 & 77.121 & 2 & 154.241 & $\begin{array}{c}\text { Positive } \\
\text { Affect }\end{array}$ \\
\hline 0.803 & 0.0001 & 73.385 & 621.236 & 2 & 1242.472 & $\begin{array}{c}\text { Negative } \\
\text { Affect }\end{array}$ \\
\hline 0.797 & 0.0001 & 70.527 & 2805.382 & 2 & 5610.765 & Aggression \\
\hline 0.690 & 0.0001 & 40.147 & 614.319 & 2 & 1228.638 & $\begin{array}{c}\text { Emotion } \\
\text { Regulation }\end{array}$ \\
\hline
\end{tabular}

As indicated in the significant levels column, there was a significant difference between the three groups in terms of individual dependent variables at the level $(\mathrm{P}<0.0001)$. Accordingly, it can be said that all the subsidiary hypotheses of the study are also statistically confirmed. Another sub-analysis after multivariate and univariate analysis of variance that should be performed after the analysis of variance, whether multivariate or univariate, (if the independent variable has more than two levels) is a pairwise comparison of groups. If the analyst wishes to compare two groups (independent variable levels), one should use post hoc tests. Here the three groups are compared in pairs and terms of each of the dependent variables, and the results are presented in Table 7. 
Table 7- Paired comparison of variables

\begin{tabular}{|c|c|c|c|c|c|}
\hline The dependent variable & Group(I) & Group(J) & Mean Difference (I-J) & standard error & P \\
\hline \multirow{3}{*}{ Self-Harm } & \multirow{2}{*}{ Control } & DBT & 5.401 & 0.545 & 0.0001 \\
& & CBT & 5.419 & 0.560 & 0.0001 \\
\cline { 2 - 6 } & DBT & CBT & 3.017 & 0.545 & 0.015 \\
\hline \multirow{3}{*}{ Positive Affect } & \multirow{2}{*}{ Control } & DBT & -3.516 & 0.888 & 0.0001 \\
& & CBT & -4.714 & 0.913 & 0.0001 \\
\cline { 2 - 6 } & DBT & CBT & -1.198 & 0.889 & 0.186 \\
\hline \multirow{3}{*}{ Negative Affect } & \multirow{2}{*}{ Control } & DBT & 12.285 & 1.120 & 0.0001 \\
& DBT & CBT & 11.566 & 1.151 & 0.0001 \\
\cline { 2 - 6 } & \multirow{2}{*}{ Control } & DBT & -0.718 & 1.121 & 0.526 \\
\hline \multirow{3}{*}{ Aggression } & CBT & -20.966 & 2.428 & 0.0001 \\
& \multirow{3}{*}{ EBTotion Regulation } & CBT & -7.564 & 2.496 & 0.0001 \\
\cline { 2 - 6 } & \multirow{2}{*}{ Control } & DBT & -12.888 & 1.506 & 0.004 \\
\cline { 2 - 6 } & DBT & CBT & -10.325 & 1.548 & 0.00001 \\
\hline & CBT & 4.563 & 1.506 & 0.038 \\
\hline
\end{tabular}

As can be seen, a Comparison of the experimental and control groups showed a significant difference $(\mathrm{P}<0.0001)$. That is, both dialectical behavior therapy and cognitive-behavioral therapy have the same effect, and neither is superior to the other. The only exception is the dependent variable of emotion regulation, aggression, and self-harm behavior that dialectics have had the greatest impact on. Referring to the descriptive data table, it is observed that in the (cognitive-behavioral) group the mean scores of the subjects were 108.27, while the mean scores of the subjects in the (dialectic) group were 100.67. Since the goal of therapeutic intervention in the variables of emotion regulation, aggression, and self-harming behavior is to reduce this psychological factor, then dialectic treatment has a greater effect on these components.

This study was aimed to compare the effectiveness of cognitive-behavioral therapy with dialectical behavior therapy on emotion regulation, positive and negative affection, aggressive and selfharm behaviors in 13-16-year-old female students. The main hypothesis of this study was that there is a difference between dialectical behavior therapy and cognitive-behavioral therapy on emotion regulation, positive and negative affect, aggressive and self-harm behaviors in female students. Multivariate analysis of covariance was used to analyze this hypothesis. The test was significantly based on all four variables. Therefore, the main research hypothesis at the level $(\mathrm{P}<0.0001)$ is confirmed. To further explain the findings of the study, subsidiary hypotheses were formulated and analyzed by one-way tests. There was a difference in the comparison of the effects of cognitive-behavioral therapy with dialectical behavior therapy on emotion regulation in female students. Univariate analysis of covariance was used to investigate the effect of cognitive-behavioral therapy and dialectical behavior therapy on emotion regulation. By examining the mean scores of the three groups, it is observed that the mean of the control group in the emotion regulation variable is 30.43 , in the dialectic group it is 46.27 and in the cognitivebehavioral group, it is 42.93 .

According to the test results, the difference between the three groups at the level $(\mathrm{P}<0.0001)$ is significant. This finding is consistent with many similar studies such as Taghizadeh, Ghorbani, and Safarinia (2015), on the effectiveness of dialectical behavioral emotion regulation techniques on Emotion Regulation Strategies for Women with Borderline Personality Disorders and drug Abuse Disorders: Multiple baseline designs showed that dialectical behavioral therapy reduced scores on negative emotional regulation strategies in women with comorbid borderline personality disorders and substance 
abuse. Emotion regulation skills include identifying emotions, understanding emotions, reducing emotional vulnerability, and reducing emotional distress. These skills help people to identify their emotions more accurately and to be able to see them without engaging in disturbing emotions. The purpose of these skills is to regulate or modify one's emotions without expressing a negative or destructive reaction (Miller, Rathus \& Linehan, 2006). In examining the comparison between cognitive behavioral therapy and dialectical behavior therapy, there was a difference in positive affect on female students in the three groups at the level $(\mathrm{P}<0.0001)$ was significant. This hypothesis was consistent with many similar studies, such as the results of Mazloumi Rad and Khanzadeh's (2016) study of the effectiveness of cognitive-behavioral group training on changing positive attitudes of female high school students on drug abuse in the region number 5 of Tehran has shown that female students undergo cognitive group training with drug abuse behaviors show a more positive attitude toward drug abuse compared to students who did not receive this training. In a controlled study in Australia about the effectiveness of dialectical behavior therapy on general mental health and positive affect of married women showed that dialectical behavior therapy significantly improved their mental health and its components and improved positive effect (Pasieczny \& connor, 2011). Comparison of the effect of cognitive-behavioral therapy with dialectical behavior therapy on the negative effect of female students showed that the mean of the control group in the negative effect variable was 32.29, in the dialectical behavior therapy group the mean scores were 19.13 and in the mean cognitive behavioral therapy group, the mean scores are 19.47. This finding is consistent with other research, including the results of Neacsiu, Rizvi and Linehan's (2010) study of the effectiveness of dialectical behavior therapy skills in reducing depression, suicidal behaviors, and anger control in patients with borderline personality disorder suggesting a significant effect of dialectical behavior therapy in reducing depression, Suicidal behaviors and anger control in patients with a borderline personality disorder. Sharma, Seine, and Sharma, Singh and Sharma's (2016) research on the effectiveness of Cognitive-Behavioral Therapy on Aggression, Negative Emotion, and Quality of war Wounded injured people's Life in Germany showed that cognitivebehavioral therapy significantly reduced aggression, negative emotions, and increased quality of life in war-injured at the post-test stage it is followed up. Negative excitement indicates unpleasant entertainment and a feeling of irritability against sedation. There is a high negative emotion in the form of unpleasantness, irritability, and anger.

Negative emotion refers to a system of "annoying motivation" that triggers punishment, and in principle, negative emotion and unpleasant emotion contribute to "avoidant behavior" (Diestel and Schmidt, 2010). There was a difference between the effects of cognitive-behavioral therapy and dialectical behavior therapy on the aggressive behavior of female students. Comparison of the mean scores of the three groups showed that the mean of the control group in the aggressive behavior variable was 74.43 , in the dialectical behavior therapy group the mean score was 100.67 and in the cognitive behavioral therapy group, the mean was 108.27. These findings were consistent with other research, such as the results of Zamani, Ahmadi, Atai-Moghanloo, and MirShekar (2014) study on the comparison of the effectiveness of two dialectical behavioral and cognitive-behavioral therapies on improving the symptoms of impulsive behaviors in patients with major depressive suicidal ideation showed that dialectical behavior therapy on reducing impulsive behaviors in patients with the major depressive disorder may lead to suicide more effectively than cognitive-behavioral therapy. The results of Dennis and Ben Porath's (2010) study of teaching dialectical behavior therapy skills to parents on their emotional regulation problems showed that this treatment significantly improves and regulates the emotions of parents. Cognitive researchers believe that between the events and emotions that individuals feel there are a cognitive process and the type of emotion that individuals experience in a situation depends on the cognitive processes in which the situation is activated. What determines the behavior and actions of individuals is the cognitive processes and the interpretation that individuals have in a given situation (Comer, 2009). Dialectical behavior therapy interventions often focus on changing the function of a behavioral problem and may not always change the problem or frequency of a behavior. As a result, unlike standard cognitive-behavioral treatments that generally address changing emotions and disturbing

Comparative Effectiveness of Cognitive-Behavioral Therapy and Dialectical Behavior Therapy on Emotion Regulation, Positive and Negative 
events, the emphasis of dialectical behavior therapy is on learning to tolerate emotional pain. Since people's aggression is often associated with their emotions, dialectical behavior therapy will be effective. Therefore, although both methods reduce aggression, dialectical behavior therapy and its techniques are more effective in reducing aggression. There was a difference in the comparison between the effects of cognitive-behavioral therapy with dialectical behavior therapy on the self-harm behavior of female students. The mean scores of the three groups showed that the mean of the control group in the self-harm behavior variable was 29.14, in the dialectical behavior therapy group the mean score was 21.33 and in the cognitive behavioral therapy group, the mean score was 24.87. Similar to the results of Kealli and Kadden's (2013) study on the effect of cognitive-behavioral group therapy on self-harm behaviors and sleep quality of patients with substance use disorder, group cognitive-behavioral therapy significantly reduced self-harm behaviors and improved sleep quality of patients. Self-harm involves repeated bodily harm such as head beating, bashing, biting, scratching or tearing skin and devouring harmful or dangerous substances, or in other words deliberate, non-fatal, or poisoning, with the knowledge of its potential danger. Self-harm is a potential behavioral disorder and it is a reactionary response to the stimuli and the person doing this wants to interact with others to be taken into consideration and is, in fact, a kind of internal disclosure. People who commit self-harm and aggressive behaviors are less likely to tolerate distress than others. People with disturbing emotions often resort to ineffective and unhealthy reactions to cope with pain because of their lack of rational thinking, and it is understandable. Distress tolerance skills help these people cope better with disturbing events.

\section{Conclusion}

Positive and negative emotions are psychological components that affect mental health. Positive emotions reflect the level of passion for life and the sense of individuality and awareness. Negative emotions, on the other hand, represent a general dimension of unhappiness and unpleasant and include unpleasant situations such as anger, hatred, guilt, fear, and anger (Spindler, Denollet, Kruse \& Pedersen, 2009). As mentioned in the present study, the comparison between the effectiveness of cognitivebehavioral therapy and dialectical behavior therapy to the results of this study, which is in line with other researches in this field, can be made using the principles and techniques of cognitive-behavioral therapy such as: (Socratic questioning, cognitive reconstruction, model teaching paying attention to thoughts and beliefs, paying attention to physical and emotional cues, paying attention to pre-emotion thoughts and beliefs, paying attention to post-thought behaviors, helping to change thinking and examining some of the basic ideas, etc.As well as dialectical behavioral therapy techniques such as mindfulness skills, effective interpersonal skills training that includes strengthening saying no skills-the ability to maintain relationships and maintain self-esteem, training distress tolerance skills (aggression and self-harm), etc. Emotional adjustment and emotion regulation training in individuals, especially adolescents who are exposed to multiple negative emotions, preventing many of their self-harming behaviors, and increasing positive emotions and emotion regulation and regulation in this group of individuals. Prevention and treatment of psychosocial and social trauma is the best move used in medical clinics, education, etc.

\section{References}

Baker, L., \& Scarth, K. (2012). Cognitive -behavioral therapy for conduct disorder. Edition six, U.S.A.

Balzarotti, S., John, OP., \& Gross, JJ. (2010). An Italian adaptation of the emotion regulation questionnaire. European Journal of Psychological Assessment,26 (1), 61-67.

Ben-Porath, DD. (2010). Dialectical behavior therapy applied to parent skills training: Adjunctive treatment for parents with difficulties in affect regulation. Cogn and Behav Pract, 17(4),458-65. 
Berking, M., Orth, U., Wupperman, P., Meier, LL., \& Caspar, F.(2008). Prospective effects of emotionregulation skills on emotional adjustment. J Couns Psychol, (55), 485-494.

Comer, J. R .(2009). Abnormal psychology. Edition Fourth U.S.A.

Diestel, S., \& Schmidt, L. (2010). Interactive effects of emotional dissonance and self-control demands on burnout, anxiety, and absenteeism. Journal of Vocational Behavior,77, 412- 424.

Fekri, SH. (2015). Relationship of negative emotion and self-concept with self-harm behaviors in bully teenagers. [MA.thesis]. Ahwaz: Payamnoor university.

Foroughi, E. (2017). The Relationship between Emotional Regulation and Hardiness with Negative Affect and Aggression in Students. [MA.thesis]. Dezfool: Payamnoor university.

Fosca, G. M. (2008). Beyond the parent-child Dyad: Testing family systems influences on children's emotion regulation. Doctoral Dissertation of Philosophy, Marquette University, Milwauke, Wiscansin.P.P.325.

Ghadiri, M.H .(2006) . Anger management. Marefat Journal, 14, 93-106.

Ghasempour, A., Ilbeigi, R., \& Hassanzadeh, Sh. (2012). Psychometric properties of the Cognitive Emotion Regulation Questionnaire in a sample of Iranian population. The sixth congress of Students mental health, university of Guilan, 722-724.

Gross, J.J.(2001). Emotion regulation in adulthood: Timing is everything. Current directions in psychological science,10(6), 214-9.

Gusman, M.R. (2014). High risk behavior among youth. Neb guide, University of Nebraska.

Hosin, A.A. (2001). Children of traumatized and exiled refugee families: resilience and vulnerability. A case study report. Med Confl Surviv, 17(2),137-45.

Kealli, G., \& Kadden, L. (2013). The impact of cognitive behavior group therapy on self-injury behavior and sleep quality in people with substance use disorder. Personality and Individual Differences, 38 (7), 1631-1643.

Khodayari, D. (2014). The study of impressive factors on domestic violence of husbands against wives in two different groups who referred to forensic medical center and female teachers in education system. [MA. thesis]. Faculty of Social Sciences, Shahed University.

Kortte, K.B., Gilbert, M., Gorman, P., \& Wegener, S. T. (2010). Positive psychological variables in the prediction of life satisfaction after spinal cord injury. Rehabil Psychol, 55(1), 40-47.

Linehan, M., \& Dexter-Mazze, E. (2012). Dialectical behavior therapy for borderline personality disorder. Clinical handbook of psychological disorders: A step-by-step treatment manual, 136(2),365-462.

Mazloumirad, M., Khanzadeh, F. (2016). The effectiveness of cognitive-behavioral group training on changing positive attitudes of female high school students on drug abuse in the region number 5 of Tehran. [MA.thesis]. Tonekabon: Islamic Azad university. 
McDermott, MJ., Tull, M.T., Gratz, K.L., Daughters, S.B., \& Lejuez, C.W. (2009). The role of anxiety sensitivity and difficulties in emotion regulation in posttraumatic stress disorder among crack/cocaine dependent patients in residential substance abuse treatment. J Anxiety Disord, 23(5),591-599.

Miller, A.L., Rathus, J.H., Linehan, M.M. (2006). Dialectical behavior therapy with suicidal adolescents. Guilford Press.

Mohammadi, A., Birashk, B., Gharraee, B. (2013). Comparison of the effect of group transdiagnostic treatment and group cognitive therapy on emotion regulation. Iranian Journal of Psychiatry \& Clinical Psychology, 19(3), 187-194.

Mohammadi, N. A preliminary study of the psychometric properties of Buss and Perry's aggression questionnaire. Journal of social sciences and humanities of Shiraz university. 2007;25(4):135-151.

Narimani, M., Bagiyan-Kulemarez, M.J., Ahadi, B., \& Abolghasemi, A. (2014). The study of effectiveness of group training of dialectical behavioral therapy (DBT) on reducing of symptoms of attention deficit /hyperactivity disorder (ADHD) and promoting quality of life of students. Journal of Clinical Psychology, 1(21), 37-49.

Nasirzadeh, R., \& Roshan, R. (2010). The effect of storytelling on aggression in six to eight-year old boys. IJPCP, 16 (2),118-126.

Neacsiu, A.D., Rizvi, S.L., \& Linehan, M.M. (2010). Dialectical behavior therapy skills use as a mediator and outcome of treatment for borderline personality disorder. Behav Res Ther,48(9),832-9.

Pasieczny, N., \& Connor, J. (2011). The effectiveness of dialectical behavior therapy in routine public mental health settings: An Australian controlled trial. Behav Res Ther, 49(1),4-10.

Ramazani, R., Rahmaninia., \& Boroumand, M.R. (2009). The study of disclosure of aggressive behaviors among "Pegah Club" soccer players in professional league competitions in Iran. Journal of sport management,1(4), 101-117.

Rosenhan, L. D., \& Seligman, E. P. M. (2012). Abnormal psychology. Third Edition. New york.

Sadeghi, H., Shahri, M., Khalrghi, N., Asadian, Z., \& Pirani, Z. (2015). Investigation the role of negative emotion regulation and educational enthusiasm in predicting of risky behavior of students. Journal of Health Breeze, 3(4), 37-44.

Seif, A A. (2014). Behavioral changing and behavioral therapy, theories and methods. Tehran. Dana publication.

Shakibaei, F., Tehrani-doust, M., Shahrivar, Z., \& Asaari, S. (2004). Anger management group therapy with cognitive behavior approach in institution adolescents. Advances in Cognitive Science, 6 (1 and 2),59-66.

Sharma, R. K., Singh, B., \& Sharma, S. (2016). The efficacy of cognitive behaviour therapy on quality of life in the amputees. The International Journal of Indian Psychology, 3 (7), 118-129.

Spindler, H., Denollet, J., Kruse, C., \& Pedersen, S.S. (2009) Positive affect and negative affect correlate differently with distress and health-related quality of life in patients with cardiac conditions: validation of the Danish Global Mood Scale. J Psychosom Res,67(1),57-65. 
Sukhodolsky, D.G., Kassinove, H., \& Gorman, B.S. (2004). Cognitive behavioral therapy for anger in children and adolescents: a mata-analysis. Aggress Violent Behav, 9(3), 247-269.

Taghi-Zadeh, M.E., Ghorbani, T., \& Safarinia M. (2015). Effectiveness of emotion regulation techniques of dialectical behavior therapy on emotion strategies in women with borderline personality disorder and substance abuse disorder: multiple baseline design. Rph, 9(3),66-73.

Tahbaz-Hoseinzadeh, S., Ghorbani, N., \& Nabavi, S.M. (2011). Comparison of self-destructive tendencies and integrative self-knowledge among multiple sclerosis and healthy people. Contemp Psychol, 6,35-44.

Watson, D., Clark, L.A., \& Tellegen, A. (1998). Development and validation of brief measures of positive and negative affect: The PANAS-scales. Journal of personality and social psychology, 54(6),10631070.

Yosefi, J. (2015). The relationship between emotional regulation and positive and negative emotion with psychological well-being of students. J Neyshabur Univ Med Sci, 3 (1), 66-74.

Zamani, N., Ahmadi, V., Ataaei-Moghanloo, V., \& Mirshekar, S. (2014). Comparing the effectiveness of two therapeutic methods of dialectical behavior therapy and cognitive behavior therapy on the improvement of impulsive behavior in the patients suffering from major depressive disorder (MMD) showing a tendency to suicide. Sjimu, 2(5), 45-54.

\section{Copyrights}

Copyright for this article is retained by the author(s), with first publication rights granted to the journal.

This is an open-access article distributed under the terms and conditions of the Creative Commons Attribution license (http://creativecommons.org/licenses/by/4.0/). 